\title{
Corporate Lawsuit, Red-hat Executives and Commercial Credit Based on the Empirical Evidence of Chinese Listed Companies
}

\author{
Yongkui Li, Yanji Mao, Zhiying Chen
}

Economics School, Southwest University of Political Science \& Law, Chongqing 401120, China

\section{公司诉讼、高管 “红顶”与商业信用 \\ 一基于中国上市公司的经验证据}

李永奎, 毛彦雯, 陈志英

西南政法大学, 经济学院, 重庆 401120, 中国

\begin{abstract}
This article takes listed companies in Shenzhen \& Shanghai A-stock markets from 2007 to 2015 as a research sample, and empirically studies the influence of the red-hat executives and corporate lawsuit on its commercial credit. The results show that the average number of the companies' senior executives with red-hat has significantly decreased after 2013.The red-hat executives can really promote the company's commercial credit, and corporate litigation has negatively affected the company's commercial credit. At the same time, the negative effect of lawsuit is more significant than the positive effect of the executive's red-hat status.
\end{abstract}

Keywords: Corporate Lawsuit; Red-hat Executives; Commercial Credit; Credit Dependence

\section{摘要}

本文以深沪 A 股市场 2007-2015 年上市公司 为研究样本, 实证研究公司的法律诉讼和高管 “红顶” 对其商业信用的影响。结果表明, 公司 高管 “红顶” 身份的均量在 2013 年后出现聚减 现象, 高管 “红顶” 身份对公司提升商业信用具 有促进作用, 而公司诉讼给公司的商业信用带来 负面影响。同时, 公司诉讼的负面效应比高管“红 顶”身份所带来的正面效应影响更为显著。
关键词: 公司诉公; 高管 “红顶”; 商业信用; 信 用依赖

1. 引言

当前我国经济发展正处于新常态和转型升 级的关键期, 各种不确定因素与市场的激烈竞争 使得所有公司将面临重大挑战，进而致使公司商 业信用的作用更加显现。商业信用是公司的良好 商业资本, 它能够替代传统的银行贷款等融资手 段 ${ }^{[1]}$ (Ge,Qiu., 2007), 使得招商引资变得更为 容易。商业信用有助于降低交易成本 ${ }^{[2]}$ (Long 等, 1993 ), 也能促进企业间的竞争 ${ }^{[3]}$ (Giannetti, 等, 2011)。商业信用是公司经营、融资以及商品交 易等行为赖以存在的基础, 需要许多具体的制度 促进和保障, 体现出其具有制度依赖性。特别地, 作为正式制度的法律制度是维护公司商业信用 健康运行的基石, 也是解决公司间由商业信用引 起争端的根本工具。同时, 公司的政治关联行为 等非正式制度对商业信用亦有重要影响, 比如公 司管理层身份标签具有的 “红顶” 身份可能有助 于提升其商业信用, 进而增强其融资能力, 也为 公司获取政府资源和庇护提供便利渠道。因此, 商业信用作为衡量公司发展稳定和潜力的一个 重要尺标, 公司所面临的法律诉讼及其高管身份 都影响其商业信用, 但它们所产生的效果不尽相 同。

随着我国法律制度建设的不断完善和市场 激烈的竞争, 公司的法制意识的不断增强, 其商 
业行为受到法律制度的监督和保护。公司为了保 护自身利益和竞争力, 当其合法权益遭到侵害 时, 公司间低效率的谈判和利益的冲突, 致使公 司只能通过法律诉讼解决由商业信用引起的争 端。在公司被提起法律诉讼之后, 其商业信用会 受到很大冲击, 进而降低公司的融资能力。公司 的外在和内在特征影响公司诉讼的效果不尽相 同, 如声誉较高的企业被诉的可能性较低, 一旦 遭遇诉讼其经营业绩下滑更甚 ${ }^{[4]}$ (Atanasov 等, 2012); 公司的内部控制越有效, 涉诉次数和涉 诉金额越低, 面临的诉讼风险越低 ${ }^{[5]}$ (毛新述和 孟杰, 2013)。因而, 在公司的治理过程中必须 重视和遵守法律制度, 才能有效地规避发生法律 诉讼风险, 增进公司的竞争力。

公司作为微观经济主体的主要表现形式, 为 了在正式制度和非正式制度的双轨制环境下更 好地生存和发展, 必定需要处理好政商关系。在 这样的环境下, 不少上市公司采取 “雇佣” 和 “鼓 励” 的两种方式使得高管具有 “红顶” 身份, 即 雇佣政府官员、行业协会领导人员等方式担任公 司高管或鼓励公司高管成为政府官员、行业领导 人员等方式, 协调和处理公司与政府的关系。但 是公司终究是从事商业活动的主体, 它们与市场 的距离会依据对政府、行业协会的依赖程度的加 深而远离, 使得它们的市场竞争能力得以削弱 ${ }^{[6]}$

(陶厚永等, 2016)。政府作为宏观经济政策的 主要制定者, 如果公司率先掌握其动机, 不仅能 降低其成本, 而且能在市场上抢占先机, 使得制 定的发展规划方案更为合理, 在市场竞争中取得 先发优势。同时，行业协会作为政府与公司之间 沟通的纽带和桥梁, 它们在对自己的公司履行监 督职能时, 也会出于私心而适当放宽监督或者有 失公正性, 使得其公司获得更多的利益。因此, 高管 “红顶” 身份会影响投资人对公司的信任程 度、公司盈利和发展的确信力, 即公司的商业信 用。

公司的商业信用是公司经营质量的一种信 号, 与外部的银行信贷形成一种传导效应, 可能 致使公司面临一系列风险。特别地, 诉讼风险将 影响公司的商业信用, 进而导致公司的经营出现 问题。法律诉讼和高管 “红顶” 身份对公司的商 业信用有何影响? 这些问题是当前公司经营中 所面临的重要问题。为此, 本文通过实证分析深 沪 A 股市场 2007-2015 年上市公司的数据, 探讨
公司诉讼、高管 “红顶” 身份以及二者共同作用 对公司商业信用的影响, 研究表明公司诉讼的负 面效应比 “红顶” 身份带来的正面效应影响更 为显著。

\section{2. 提出假设}

由于公司内外部协商机制难以发挥作用或 者沟通不畅, 相关主体为了维护自身的经济利 益, 从而通过法律诉讼解决其争端。公司被起诉 次数越多, 其商业信用所打的折扣会越大, 致使 投资者综合考虑投资风险和回报率，谨慎处理该 公司的投资活动。当公司败诉后，其商业合作伙 伴会对公司的经营产生质疑，进而可能导致公司 陷入资金短缺的困境, 降低了其商业信用。 Engelmann 和 Cornell (1988) ${ }^{[7]}$ 通过对比研究原 告和被告的股价, 发现被告股价下跌幅度较大, 而原告的股价轻微上涨, 被告公司存在严重的价 值流失, 进而使其商业信用受到较大的影响。同 时, 公司诉讼通常是零和博弯, 败诉企业的损失 可能远大于胜诉企业的获益, 并且中间存在大量 资源浪费 ${ }^{[8]}$ （Tan D., 2016）。当公司面临法律诉 讼时, 如果其败诉所带来的诉讼费用负担导致成 本的提高, 并严重影响公司的信用, 进而可致使 其资金链断流，公司的发展将会难以实现或者可 能面临破产。因此, 公司一旦面临诉讼风险, 将 对公司的商业信用产生负面影响。为此, 提出如 下假设:

假设 1：当其他条件不变的情况下，公司诉 讼会对其商业信用产生负面影响。

公司高管的 “红顶” 身份作为一种非正式 制度, 增强了以社会信任和网络关系为核心的社 会资本, 从而为获取商业信用提供了社会信用基 础与担保机制 ${ }^{[9]}$ (罗劲博, 2016)。同时, 公司的 政治关联具有社会负担效应、产权保护效应以及 政府偏祖效应 ${ }^{[10]}$ (田利辉, 张伟, 2013)。公司 高管利用其特殊身份, 能第一时间把握政策导向 和市场动向, 使公司获得较大经济收益, 进而提 升公司的商业信用。总之, 公司高管的 “红顶” 身份不仅可使其拥有信息和资源，而且拥有控制 和适时使用信息资源等诸多优势, 为公司创造诸 多难得的机遇 ${ }^{[11]}$ (边燕杰和丘海雄, 2000)。公 司存在的这种抽象特殊资本, 在公司运营中起到 了中流砥柱的作用, 成为一种以信用为基础的隐 性担保机制。因此, 公司高管的 “红顶” 身份对 其商业信用有积极作用, 本文提出如下假设: 
假设 2：公司高管 “红顶” 身份对公司商业 信用的提升具有促进作用。

随着法律制度的不断完善和市场化的加速 发展, 政治关联对企业的积极作用正在被其消极 作用所抵消 ${ }^{[12]}$ (王永进等, 2012)。在优胜劣汰 的市场竞争体制下，信息不对称导致公司间的竞 争强度不断增大, 具有高管 “红顶” 身份的公司 更能发挥其特有优势。高管 “红顶” 身份是一种 特殊的社会资本, 它对平衡交易双方心理、稳定 未来预期以及赢得彼此信任等发挥着不可替代 的作用。公司高管的身份具有政治影响力, 此种 政治关联可以缓解公司所面临的融资约束 ${ }^{[13]}$

(Chan 等, 2012)。它不仅在信息获取上存在优 势, 其身份本身也是公司商业信用的象征。高管 “红顶” 身份所建立的社会关系网络, 能给公司 提供较多的信息和资源, 促使公司获得较多的经 济利益, 进而提升公司的商业信用。但是随着诉 讼逐渐成为公司之间解决矛盾的重要手段, 投资 者更加注重公司与法律诉公相关的数据。公司一 旦被提起诉公，不仅对公司的商业信用带来较大 的负面影响, 也给高管 “红顶” 身份带来一定的 冲击, 使得人们对高管 “红顶” 的信任程度降低。 同时, 地方司法保护对司法公信力的冲击, 会进 一步加深诉讼对商业信用的负面影响。由于作为 正式制度的法律制度对公司的作用和影响更大, 而高管 “红顶” 的非正式制度对公司治理的影 响相对较小。因此, 基于以上分析, 本文提出如 下假设:

假设 3: 公司诉讼带来的负面效应将大于高 管 “红顶” 身份带来的正面效应。

\section{3. 研究设计}

\section{1 数据的来源}

本文选择深沪 A 股市场 2007-2015 年上市公 司作为研究的样本, 剔除 ST、PT 企业和数据缺 失值较多的企业, 也剔除银行、保险和证券等金 融类公司, 以及对资产负债率高于 1 的样本进行 踢除后, 获得不平衡面板数据 10562 个观测值。 本文研究所使用的财务数据和高管 “红顶” 身 份信息均来自于国泰安数据库 (CMSER)。上市 公司的基本信息、持股情况以及诉讼相关数据来 自于锐思 (RESSET) 数据库, 而高管 “红顶” 身份数据经手工收集整理得到。

\section{2 变量定义}

\subsection{1 被解释变量}

商业信用: 本文衡量商业信用的指数采用付 佳 ${ }^{[14]}$ (2017) 等人使用的应付账款、应付票据和 预收账款之和与总资产的比率加以衡量。其中应 付账款和应付票据在一定程度上体现了公司的 商业信用, 而预收账款表现为公司所具有的融资 能力, 总资产作为公司存在的根基, 其比率可以 更好衡量公司的商业信用。

\subsection{2 解释变量}

（1）公司诉讼: 我国的诉讼类型可以分为 民事诉讼、行政诉公和刑事诉讼。但在我国上市 公司中最主要表现的诉讼是民事诉讼, 其他类型 的诉讼缺乏数据, 因此本文中只考虑公司在某一 民事诉讼纠纷中成为被告的情况。公司在某一年 度内被诉讼一次记作 1, 并对其一年内被提起诉 讼的次数进行加总。

（2）高管 “红顶”: 本文通过从上市公司对 高管的披露信息中篮选出在市级及以上政府部 门和行业协会任职的党政干部人员, 并对同一公 司的人员人数进行加总, 作为该公司 “红顶” 程 度的指标。

\begin{tabular}{|c|c|c|c|}
\hline \multicolumn{4}{|c|}{ 表 1 变量的控制及说明 } \\
\hline 变量类型 & 变量名称 & $\begin{array}{c}\text { 变量代 } \\
\text { 码 }\end{array}$ & 变量定义 \\
\hline $\begin{array}{c}\text { 被解释变 } \\
\text { 量 }\end{array}$ & 商业信月 & Credit & $\begin{array}{c}\text { (应付胀款十应付票搭+称收胀款) /总资 } \\
\text { 产 }\end{array}$ \\
\hline \multirow{2}{*}{ 解释变量 } & 公司诉讼 & Judge & 累计公司作为被告诉讼数量 \\
\hline & 高管“红项” & $R c$ & 累计 “红项” 高管数量 \\
\hline \multirow{7}{*}{ 控制变量 } & 公司年趋 & Age & 企业成立年数 \\
\hline & 栋金流是比 & Flow & 经营活动产生的现金流軍净额/总资产 \\
\hline & $\begin{array}{c}\text { 第一大股东持股 } \\
\text { 比 }\end{array}$ & Hold & 第一大股东所持有的股份/总股数 \\
\hline & 资产负聩率 & Lev & 负债总额/资产总䬫 \\
\hline & 公司概模 & Size & 总资产取自然对数 \\
\hline & 驽产回报率 & $R e$ & 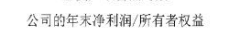 \\
\hline & 棤款水平 & Loan & （长期借款＋知期借款）／总资产 \\
\hline
\end{tabular}

\subsection{3 控制变量}

本文参考付佳 (2017) 等 ${ }^{[14-15]}$ 的研究, 并结 合本文的研究对象, 选择公司年龄 (Age)、现金 流量比 (Flow)、第一大股东持股比率 (Hold)、 资产负债率 $(\mathrm{Lev}) 、$ 公司规模 $($ Size )、资产回报 率 (Re) 以及借款水平 (Loan) 等指标作为本文 研究的控制变量。

\section{3 模型设计}

为验证前述相关假设的正确性, 并结合本文 的研究对象和研究目的, 本文提出如下模型。本 
文设计模型 (1) 为验证假设 1:

Credit $=\alpha_{0}+\alpha_{1}$ Judge $+\alpha_{2}$ Age

$+\alpha_{3}$ Flow $+\alpha_{4}$ Hold $+\alpha_{5}$ Lev $+\alpha_{6}$ Size (1)

$+\alpha_{7} \operatorname{Re}+\alpha_{8}$ Loan $+\eta_{i t}+\xi_{i t}+u_{i}$

其中被解释变量为商业信用 (Credit), 用 (应 付账款+应付票据+预收账款）/总资产来表示,

解释变量是公司诉讼 ( Judge $) 。 \alpha_{0}$ 表示截距项,

$\alpha_{i}$ 表示回归方程系数, $i=1,2,3, \ldots, u_{i}$ 表示残 差项（下同）。另外基于已有文献，控制了公司 年龄 $(A g e)$ 、现金流量比 (Flow)、第一大股东 持股比 (Hold)、资产负债率 (Lev)、公司规模

$($ Size $)$ 、资产回报率 $(R e)$ 和借贷水平 $(L o a n)$ 等因素; 同时控制了省份和行业固定效应, 如果

回归系数 $\alpha_{1}$ 小于 0 , 则表明公司诉公对商业信用

具有负面影响。

为了验证假设 2 , 设计模型 (2):

Credit $=\alpha_{0}^{\prime}+\alpha_{1}^{\prime} R c+\alpha_{2}^{\prime}$ Age

$+\alpha_{3}^{\prime}$ Flow $+\alpha_{4}^{\prime}$ Hold $+\alpha_{5}^{\prime} L e v+\alpha_{6}^{\prime}$ Size (2)

$+\alpha_{7}^{\prime} \operatorname{Re}+\alpha_{8}^{\prime} \operatorname{Loan}+\eta_{i t}+\xi_{i t}+u_{i}$

如果回归系数 $\alpha_{1}^{\prime}$ 大于 0 , 则表明高管 “红顶”

能促进公司积累商业信用。

为了验证 “红顶” 身份和诉讼对公司的商业 信用的共同作用机制, 以及假设 3 的合理性, 综 合考虑模型（1）和（2）构造模型（3）。在此基 础上, 加入公司诉讼和高管 “红顶” 的乘积项, 其余控制变量与前面模型相同, 构建模型 (4)。

如果系数 $\alpha_{3}^{\prime \prime \prime}$ 大于零, 则表明公司的诉讼次数越 多, 公司面临的诉讼风险就越大, 高管 “红顶” 身份对诉讼风险的补偿作用就越大, 越能提升商 业信用。

Credit $=\alpha_{0}^{\prime \prime}+\alpha_{1}^{\prime \prime R c}+\alpha_{2}^{\prime \prime J u d g e}+\alpha_{3}^{\prime \prime A g e}$

$+\alpha_{4}^{\prime \prime F l o w ~}+\alpha_{5}^{\prime \prime H l o d}+\alpha_{6}^{\prime \prime L e v}+\alpha_{7}^{\prime \prime S i z e}$

$+\alpha_{8}^{\prime \prime} R e+\alpha_{9}^{\prime \prime}$ Loan $+\eta_{i t}+\xi_{i t}+u_{i}$

$$
\begin{aligned}
& \text { Credit }=\alpha_{0}^{\prime \prime \prime}+\alpha_{1}^{\prime \prime \prime} R c+\alpha_{2}^{\prime \prime \prime} J u d g e \\
& +\alpha_{3}^{\prime \prime \prime} \text { JudgeRc }+\alpha_{4}^{\prime \prime \prime} \text { Age }+\alpha_{5}^{\prime \prime \prime} \text { Flow } \\
& +\alpha_{6}^{\prime \prime \prime} \text { Hlod }+\alpha_{7}^{\prime \prime \prime} \text { Lev }+\alpha_{8}^{\prime \prime \prime} \text { Size }+\alpha_{9}^{\prime \prime \prime} \text { Re } \\
& +\alpha_{10}^{\prime \prime \prime} \text { Loan }+\eta_{i t}+\xi_{i t}+u_{i}
\end{aligned}
$$

\section{4. 实证结果}

\section{1 描述性统计}

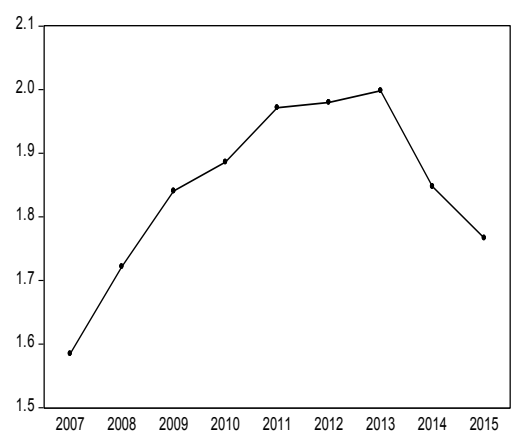

图 1 高管 “红顶” 身份人数的年均量趋势

图 1 是从 2007 至 2015 年,上市公司高管“红 顶” 身份年均量的趋势图。从 2007 年到 2009 年, 图形的斜率最大, 呈现上升趋势, 这表明在此期 间企业对高管 “红顶” 身份的需求倾向较为突 出。这是由于在此期间爆发的全球性金融危机, 致使国内各企业面临种种危机甚至倒闭的风险, 而金融机构自身面临的风险也使企业的融资问 题雪上加霜。因此, 各公司高管人员纷纷涌入政 府部门、行业协会等任职, 以此来弥补所属公司 与政府之间的信息不对称，把握政策动向和增强 公司的融资能力, 进而降低金融危机的威胁。从 2009 年到 2011 年, 各国刺激政策促使全球经济 开始复苏, 此时国内企业的经营管理仍处于谨慎 状态，而公司高管 “红顶” 身份的人数仍然处于 上升阶段, 从曲线斜率来看, 增长速度已经较为 平缓。2 011 年以后, 经济基本恢复了稳定, 其变 化趋于平缓并在 2013 年到达最高点。在 2013 年 之后, 高管 “红顶” 身份的数量开始骤减, 一年 时间约降了 0.16 , 这与我国对公司高管 “红顶” 身份管制的严格程度有关。这是由于相关制度的 完善和管制严格化，使得它对公司商业信用的促 进作用开始减弱, 从而促使部分公司开始抛弃这 一非正式制度。综上所述，该图的公司高管 “红 顶” 身份的人数走势与金融危机以及相关制度 
的完善有关。

\section{2 多元回归分析}

\begin{tabular}{|c|c|c|c|c|c|}
\hline \multirow{2}{*}{ 变量类型 } & \multirow{2}{*}{ 变量名称 } & \multicolumn{4}{|c|}{ 多元回归结果 } \\
\hline & & 模型 (1) & 模型 (2) & 㷬型 (3) & 模型 (4) \\
\hline \multirow{6}{*}{ 解释变量 } & \multirow{2}{*}{ Judge } & $-0.005 * * * *$ & & $-0.005 * * *$ & $-0.005 * * * *$ \\
\hline & & $(-7.89)$ & & $(-7.93)$ & $(.6 .51)$ \\
\hline & \multirow{2}{*}{$R c$} & & $0.001^{*}$ & $0.001^{m * n}$ & $0.001^{\prime \prime}$ \\
\hline & & & (1.83) & (1.97) & $(1.94)$ \\
\hline & \multirow{2}{*}{ JudgeRc } & & & & 0.001 \\
\hline & & & & & $(0.31)$ \\
\hline \multirow{14}{*}{ 控制变量 } & \multirow{2}{*}{ Age } & -0.004 粬里 & $-0.004^{*}$ 米舟 & $-0.004 * * * *$ & $-0.004 *$ **** \\
\hline & & $(-13.58)$ & $(-13.57)$ & $(-13.57)$ & $(-13.57)$ \\
\hline & \multirow{2}{*}{ Flow } & 0.047 ***; & 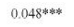 & 0.047 whistos & 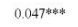 \\
\hline & & (12.13) & (1227) & (12.15) & $(12.15)$ \\
\hline & \multirow{2}{*}{ Hold } & $0.028^{* * *}$ & 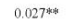 & $0.028^{\text {st }}$ & $0.028^{* * *}$ \\
\hline & & $(3.07)$ & (2.95) & (3.01) & (2.99) \\
\hline & \multirow{2}{*}{ Lev } & $0.412 * * *$ & 0.409 ***; & $0.412^{\text {米的的 }}$ & $0.412^{* * * *}$ \\
\hline & & $(64.71)$ & $(64.12)$ & $(64.72)$ & $(64.71)$ \\
\hline & \multirow{2}{*}{ Size } & $0.015 * * *$ & 0.015 *** & 0.015 被 & 0.015 **** \\
\hline & & (11.48) & $(11.62)$ & (11.31) & $(11.31)$ \\
\hline & \multirow{2}{*}{$R e$} & $-\left.0.00\right|^{* 4 * 8}$ & $-0.002^{\text {intak }}$ & $-0.001 * * * *$ & $-0.001^{\text {* whe }}$ \\
\hline & & $(.5 .16)$ & $(.536)$ & $(-5.19)$ & $(.5 .20)$ \\
\hline & \multirow{2}{*}{ Loan } & $-0.394^{\text {then }}$ & $-0.392^{\text {atata }}$ & $-0.394^{* * * *}$ & $-0.394^{* * * *}$ \\
\hline & & $(-50.75)$ & $(-50.28)$ & $(-50.69)$ & $(50.69)$ \\
\hline \multicolumn{2}{|c|}{ 省份、行业 } & 控制 & 控制 & 控制 & 控制 \\
\hline \multicolumn{2}{|c|}{$A d j-R^{2}$} & 0.3559 & 0.3600 & 0.3559 & 0.3603 \\
\hline \multicolumn{2}{|c|}{ 观测值 } & 10562 & 10562 & 10562 & 10562 \\
\hline \multicolumn{2}{|c|}{$F-$ Statistic } & $646.47^{* \text { **** }}$ & 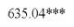 & $635.04^{\text {s*ak }}$ & 517.69 *** \\
\hline \multicolumn{6}{|c|}{ 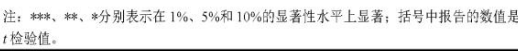 } \\
\hline
\end{tabular}

公司诉讼、高管 “红顶” 和商业信用的多元 回归结果见表 4。第一列为模型 (1) 的回归结果, 其公司诉讼 (Judge ) 的回归系数为 -0.005 ( $t$ $=-7.89$ ), 且在 $1 \%$ 的水平上显著, 说明公司诉公 会给商业信用带来直接负效应, 从而验证了本文 所提出的假设 1 。如果公司被提起诉公而败诉, 则表明公司的运营与管理已存在严重问题, 致使 其商业信用降低, 进一步影响公司的运营和发 展。因此, 公司务要完善治理机制, 有效改善治 理状况, 以提高公司治理能力来降低诉讼风险, 提升自身规避诉讼风险的能力。

模型 (2) 的回归结果表明, 高管 “红顶” 身份 $(R c)$ 的回归系数为 0.001 , 且在 $10 \%$ 的水 平上显著, 说明高管的 “红顶” 身能给商业信用 带来直接正效应, 有利于公司的经营和发展, 假 设 2 得到了验证。我国目前正处于经济转型攻坚 期, 高管的 “红顶” 身份能缓解公司所面临的信 息不对称、融资约束、以及经营危机等问题, 减 弱公司运营的压力而增强公司的竞争力。倘若公
司依靠高管 “红顶” 身份提前获取有利于自身的 市场信息, 使得公司在市场竞争中具有先发优 势, 更有可能给公司带来超额收益, 进而增强公 司的商业信用。从模型 (3) 中可以发现, 公司 诉讼 (Judge ) 和高管 “红顶” (Rc) 身份的回 归系数分别在 $1 \%$ 和 $5 \%$ 的显著性水平下显著, 并 且公司诉讼给商业信用带来的直接负效应高于 高管 “红顶” 所带来的直接正效应, 从而假设 3 得以验证。并且在加入了诉讼后, 高管 “红顶” (Rc) 身份的显著性水平由 $10 \%$ 提高到了 $5 \%$, 这表明公司在面对可能的诉讼风险时, 高管 “红 顶” 是公司不可或缺的特殊商业资本, 它以直接 增加公司商业信用的方式抵消因诉讼风险给公 司带来的直接负影响。

从模型 (4) 的回归结果来看, 加入公司诉 讼和高管 “红顶” 的乘积项后, 主要参数的回归 系数基本没有受到影响, 相比于模型 (3) 而言, 高管 “红顶” $(R c)$ 的显著性有所降低, 而公司 诉讼与模型（2）中的显著性相同。这一结果表 明, 公司诉讼、高管 “红顶” 对商业信用的作用 机理不仅体现在二者对商业信用的直接作用, 也 体现在高管 “红顶” 对公司诉讼所产生的负效 应的补偿作用上, 实质上是一种对商业信用所产 生的补偿作用间接体现。正如假设 3 所述, 该乘 积项的回归结果为正，则表明高管 “红顶” 对公 司诉公所产生的负效应具有补偿作用, 显著性不 强则表明在这个过程中, 更多体现的是高管 “红 顶” 所带来的直接正效应, 而补偿作用即间接效 应处于次要位置。这主要是由于当公司发生诉 讼, 特别在败诉之后, 对高管 “红顶” 身份冲击 并不明显, 而商业信用产生的负面效应高于高管 “红顶” 本身的直接正效应, 高管 “红顶” 对商 业信用的补偿作用并没有较大程度的表现。因 此, 公司应当依法运营, 巩固作为特殊资本的商 业信用, 促进公司健康发展, 可减少因诉讼产生 的商业信用缺失。

该结果同时也表明, 从公司面临的诉公风险 来看, 虽然高管 “红顶” 身份能够补偿公司的商 业信用, 但当公司被提起诉讼之后, 其商业信用 已经过一次折扣, 倘若败诉, 公司在诉讼费和赔 偿金的双重压力下, 其可信任度会被再次降低。 如果公司过度实行 “人治”, 监事会和工会的形 同虚设, 使得公司在面对公正判决时将不堪一 击。这也是公司诉讼对公司商业信用产生的负面 
效应大于高管 “红顶”正面效应的重要原因之一。 因而, 公司一方面应当按照法律法规的强制性规 定, 按照公司章程治理公司, 做到防范于未然。 另一方面, 应当适当使用 “人治” 弥补 “法治” 无法涉入的领域, 稳定公司的内部治理结构。

\section{5. 结论}

我国正在处于转型时期, 融资难的问题将进 一步提升。当众多的企业无法从金融等机构获得 足够的商业资本时, 商业信用则成为了缓解融资 难问题的重要途径。公司通过商业信用进行招商 引资, 吸引更多的投资者前来投资, 以满足公司 发展的资金需求。本文通过实证研究公司的法律 诉讼和高管 “红顶” 对其商业信用的影响, 研究 发现, 公司 “红顶” 高管均量呈现递减趋势, 公 司诉讼对其商业信用具有负效应, 高管 “红顶” 身份能增强公司的商业信用。同时, 公司诉讼的 负面效应比高管 “红顶” 身份所带来的正面效应 影响结果更为显著。因此, 公司在现代治理过程 中, 正确处理公司诉讼以及高管身份角色的定位 对自身发展具有重要的现实意义, 本文的研究为 公司利用商业信用融资提供新视角。

\section{Acknowledgements}

This study was supported by Humanities and Social Sciences of Ministry of Education Planning Fund, China (No.17YJC790083) and Youth Foundation of Southwest University of Political Science \& Law (No.2017XZQN-15)

\section{致谢}

本研究得到了教育部人文社会科学研究项目 (17YJC790083) 和西南政法大学科研项目 (2017XZQN-15) 的资助。

\section{参考文献}

[1] Ge Y, Qiu J. Financial development, bank discrimination and trade credit. Journal of Banking \& Finance, 2007, 31(2): 513-530.

[2] Long M S, Malitz I B, Ravid S A. On trade credit, quality guarantees and product market Ability. Financial Management, 1993, 22(4):117-127.

[3] Giannetti M, Burkart M, Ellingsen T. What you sell is what you lend? Explaining trade credit contracts. Review of Financial Studies, 2011, 24(4):1261-1298.

[4] Atanasov V, Ivanov V, Litvak K. Does reputation limit opportunistic behavior in the $\mathrm{VC}$ industry? Evidence from litigation against VCs. The Journal of Finance, 2012, 67(6): 2215-2246.

[5] 毛新述,孟杰.内部控制与诉公风险.管理世界, 2013,(11):155-165.

[6]陶厚永,李玲.高管身份跨界的“双刃剑”与民 营企业成长。管理评论，2016, 28(10):153-167.

[7] Engelmann K, Cornell B. Measuring the cost of corporate litigation: Five case studies. The Journal of Legal Studies, 1988,17(2): 377-399.

[8] Tan D. Making the news: Heterogeneous media coverage and corporate litigation. Strategic Management Journal, 2016, 37(7): 1341-1353.

[9] 罗劲博. 高管的 “红顶商人” 身份与公司商 业信用. 上海财经大学学报, 2016, 18(3):48-58.

[10] 田利辉, 张伟. 政治关联影响我国上市公司 长期绩效的三大效应. 经济研究, 2013, (11) : 71-86.

[11] 边燕杰, 丘海雄. 企业的社会资本及其功效. 中国社会科学, 2000, (2):87-99.

[12] 王永进, 盛丹. 政治关联与企业的契约实施 环境. 经济学(季刊), 2012, 11(4):1193-1218.

[13] Chan K S, Dang V Q T, Yan I K M. Chinese firms' political connection, ownership, and financing constraints. Economics Letters, 2012, 115(2):164-167.

[14] 付佳. 税收规避、商业信用融资和企业绩效. 山西财经大学学报, 2017, 39(2):87-98.

[15] Ding Y, Zhang M. Research on the Development of County Finance in Guizhou Province in the Promotion of Precise Poverty Alleviation. Journal of Risk Analysis and Crisis Response, 2018, 8(1):52-60. 